\title{
Improvement of Children Road Safety in Iran
}

\author{
Mohsen Ansari', Ali Gorji ${ }^{2,3,4 *}$ \\ ${ }^{1}$ Police University, Tehran, Iran
}

${ }^{2}$ Shefa Neuroscience Research Center, Khatam Alanbia Hospital, Tehran, Iran

${ }^{3}$ Mashhad Neuroscience Department, Mashhad University of Medical Sciences, Mashhad, Iran

${ }^{4}$ Epilepsy Research Center, Department of Neurology and Neurosurgery, Westfälische Wilhelms-Universität Münster, Münster, Germany

\section{A BSTRACT}

Introduction: Road traffic accidents account for approximately 186,300 children deaths annually as well as millions of injuries; including brain and spine trauma. Road accidents may lead to several disabilities and chronic disease, such as refractory epilepsy and cognitive impairments. In low-income and middle-income countries, road traffic accidents account for about two-thirds of these casualties and injuries. To address the importance of public health and sustainable development issue of child road safety in Iran, The Fifth International Road Safety and Pediatric Trauma was held on January 20-22, 2016 in Tehran, Iran. Conclusion: During three days of discussion between several experts from Europe as well as Iranian scientists, physicians, health educators, and traffic police on different aspects of children road safety, the followings seven points were suggested for for the improvement of children traffic safety: 1) declaration of road safety as a national health problem, 2) adoption of technical safety standards for cars and child seats, 3) codification of law for mandatory use of seat belt and child seats, 4) implementation of enforcement measures for checking seat belt and child seat use, 5) enhancement of accident research and data monitoring system country wide. Furthermore, emphases were given to protection of child pedestrians, bicyclists, 6) obligatory education on children road safety in schools, and 7) emphasizing the role of media on improvement of children road safety.

\section{Key words:}

1. Child

2. Safety

3. Education

4. Accidents

5. Brain Injuries

* Corresponding Author: Ali Gorji

E-mail:gorjial@uni-muenster.de 


\title{
بهبود ايمنى راه كودكان در ايران
}

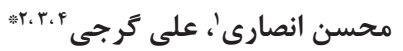 \\ 'دانشَاه علوم انتظامى، تهران، ايران \\ 'مركز تحقيقات علوم اعصاب شفا، بيمارستان خاتم الانبياء، تهران، ايران \\ "مَروه علوم اعصاب مشهد، دانشخاه علوم يزشكى مشهد، مشهد، ايران \\ †مركز تحقيقات صرع، كروه نورولوزى و جراحى مغز و اعصاب، دانشكاه مونستر، مونستر، آلمان
}

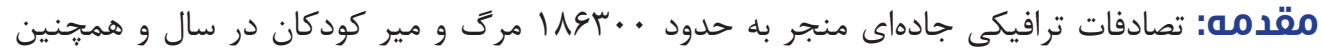

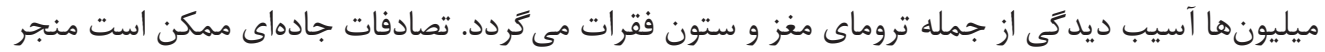

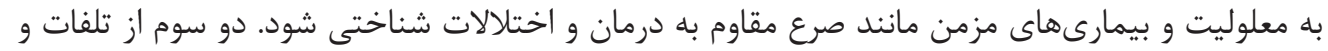

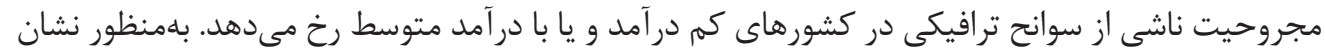

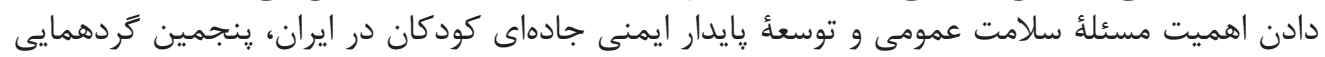

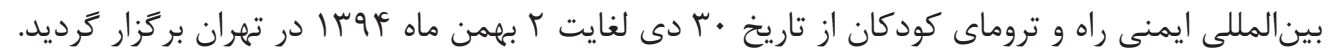

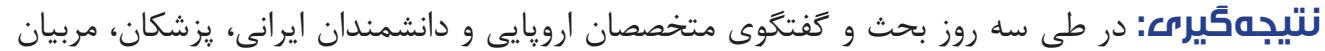

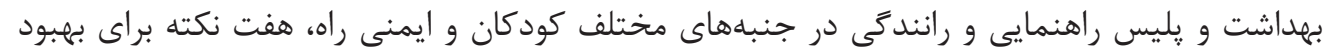

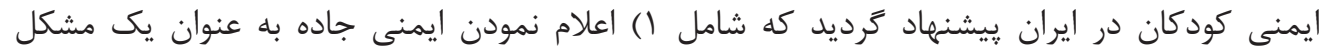

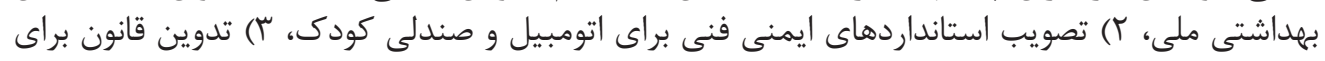

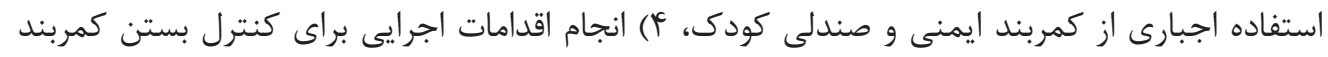

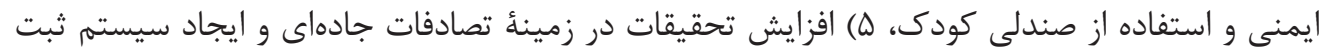

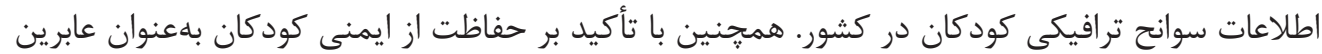

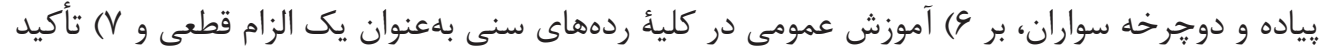

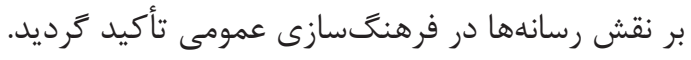

" نويسنده مسئول: على گرجى : آدرس الكترونيكى: gorjial@uni-muenster.de 
كودى يا كلاه ايمنى در حين دوجرخه سوارى وجود ندارد. قانون

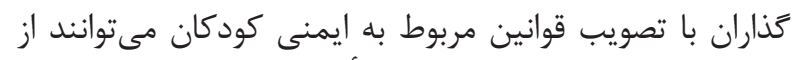

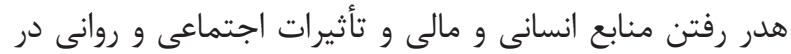
كشورمان بيشگيرى نمايند (r (I).

براى ارتقاء ايمنى كودكان در سوانح ترافيكى سازمان بهداشت

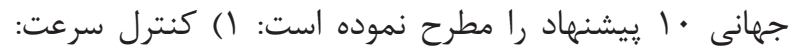

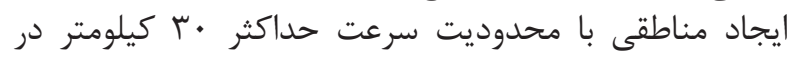

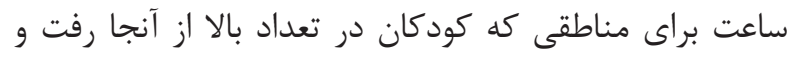

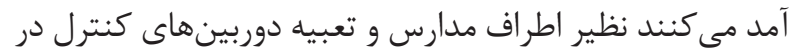

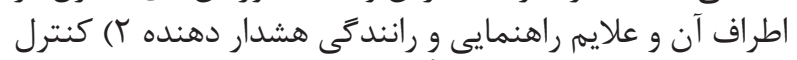

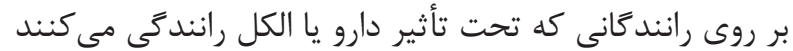

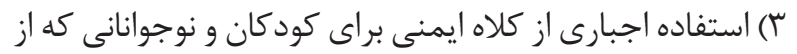

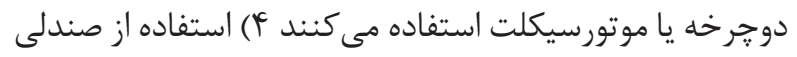

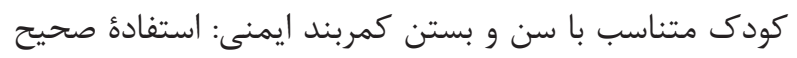

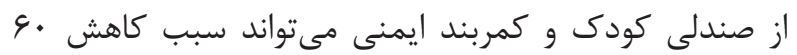

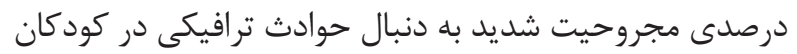

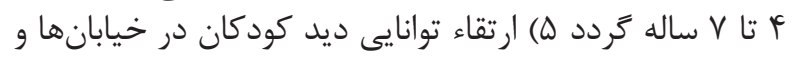

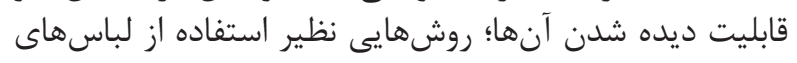

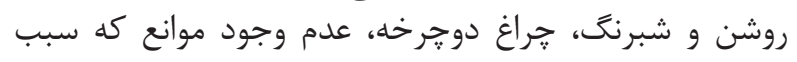

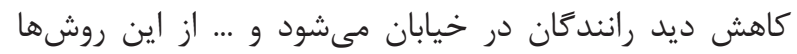

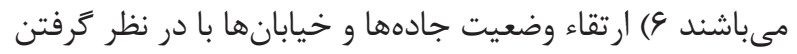

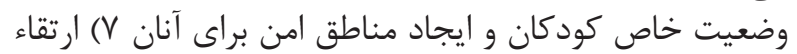

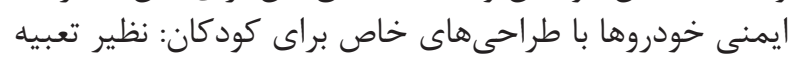

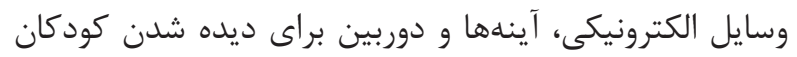

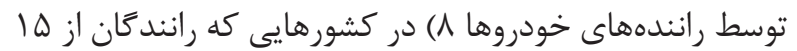

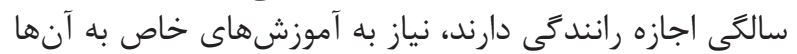

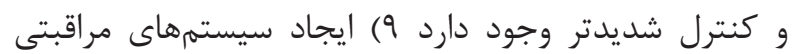

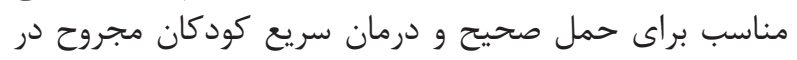

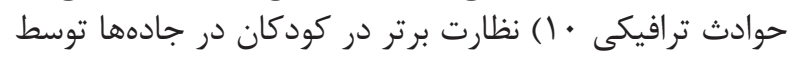
والدين، يليس، مسئولين مدارس و... († ، بار).

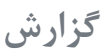

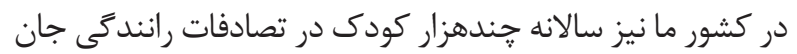

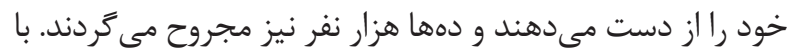

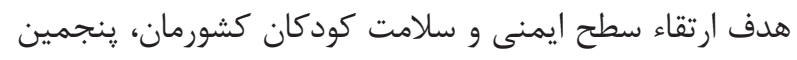

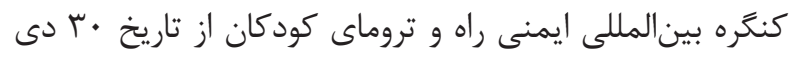

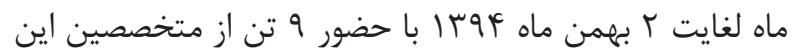

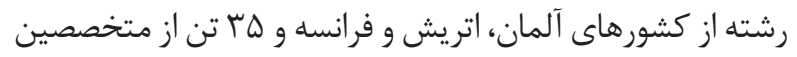

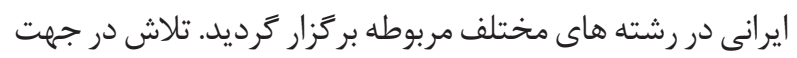

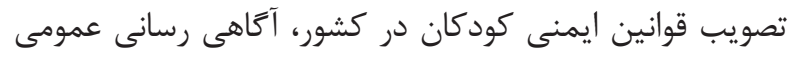

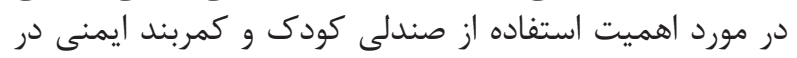

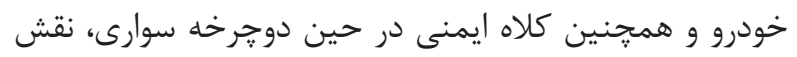

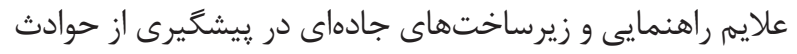

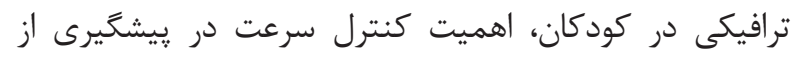

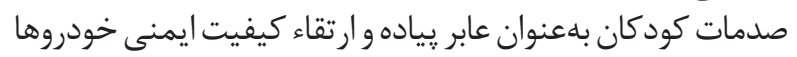

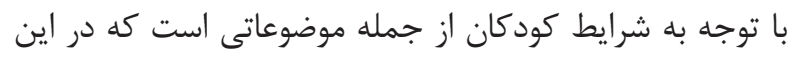

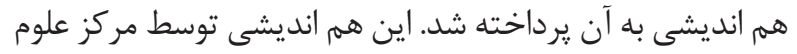
اعصاب شفا -بيمارستان خاتمالانبياء (ص) و بنياد شهيد انديد و امور علئ
مقدمه

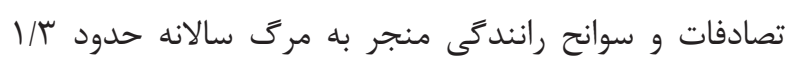

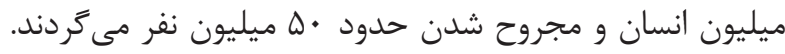

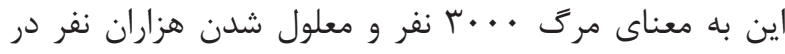

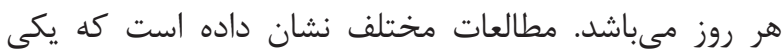

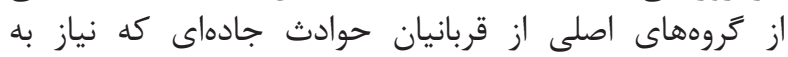

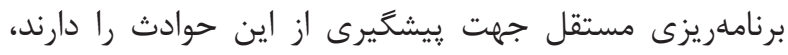

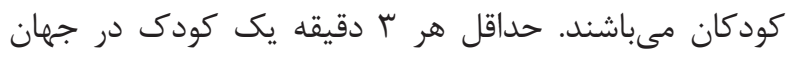

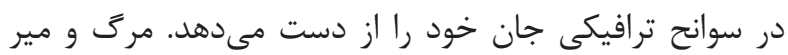

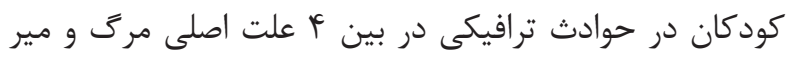

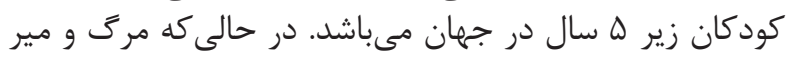

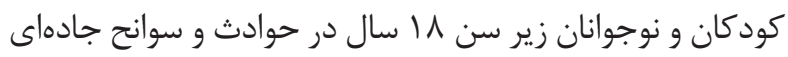

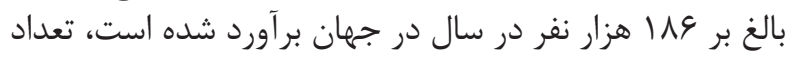

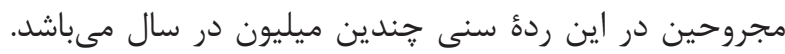

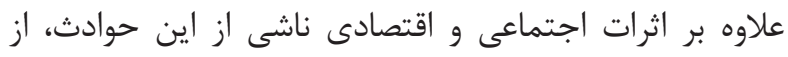

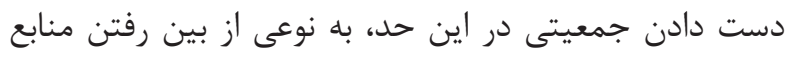

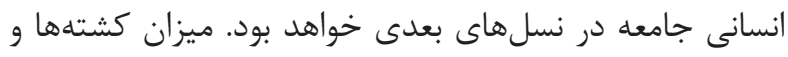

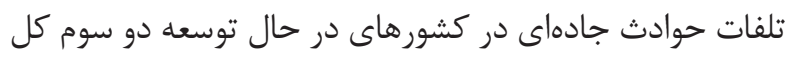
تلفات و مجروحين راد شامل مى شود (1) (1).

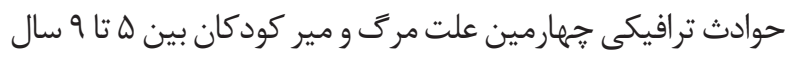

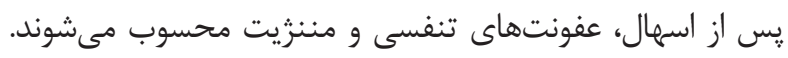

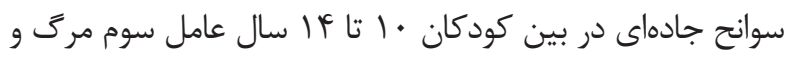

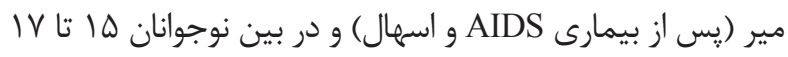

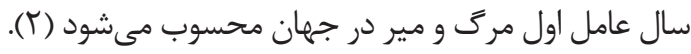

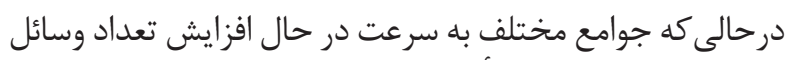

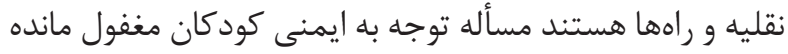

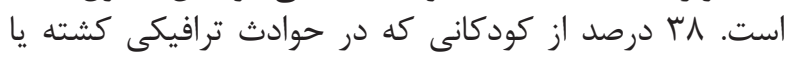

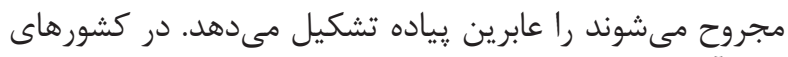

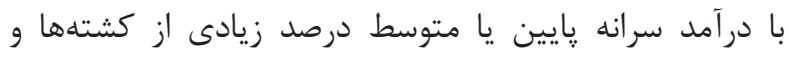

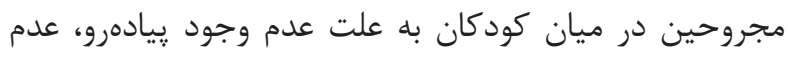

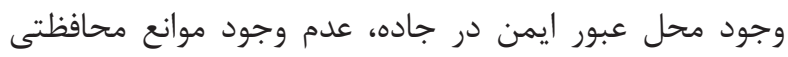

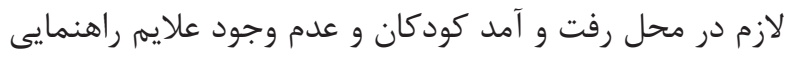

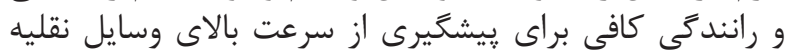

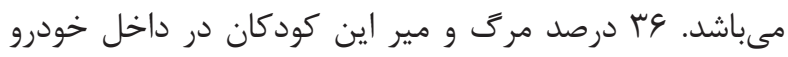

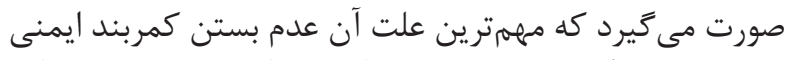

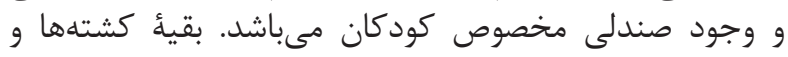

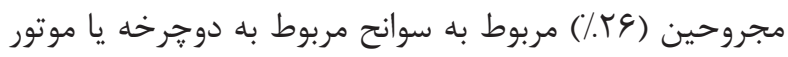

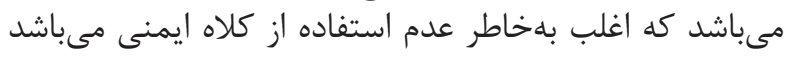

بهعلاوه اين سوانح سالانه باعث مجروح و معلول شدن ميليونها

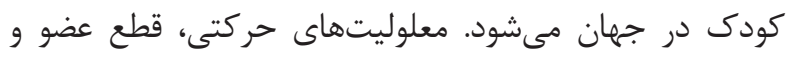

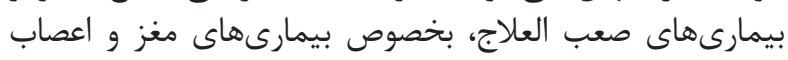

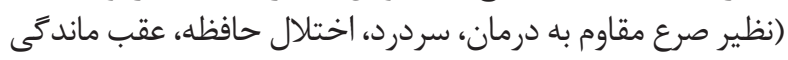

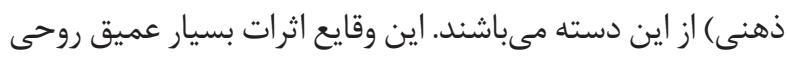

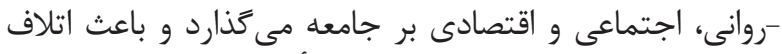

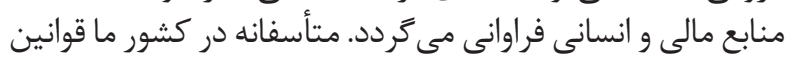

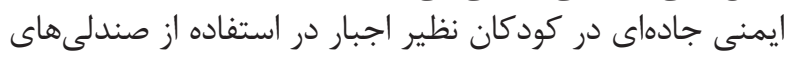


• • تدوين قانون براى استفاده اجبارى از كمربند ايمنى و

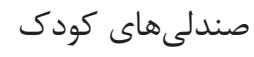

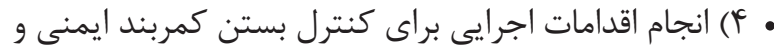

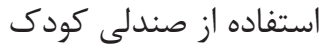

• (b) افزايش تحقيقات در زمينه تصادفات جادهاى و ايجاد

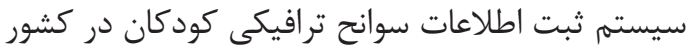
• ع) آموزش عمومى در كلئُ ردهاى سنى بهعنوان يك الزام قطعى

• • تأكيد بر نقش رسانهها در فرهنَسازى عمومى در زمينأ

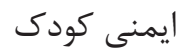

همجنين در خصوص ايمنى كودكان بهعنوان عابرين زياده و دوجرخه سواران تأكيد شد.

1. Peden M, Scurfield R, Sleet D, Mohan D, Hyder AA, Jarawan E, et al. The World Report On Road Traffic Injury Prevention. Geneva, World Health Organization; 2004.

2. World Health Organization. Dept. of Injuries and Violence Prevention. The Injury Chartbook: A graphical overview of the global burden of injuries. Geneva, World Health Organization. 2002.
ايثارگران با همكارى يليس راهور، هلال احمر و وزارت بهداشت

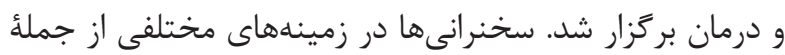

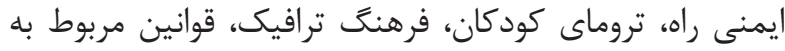

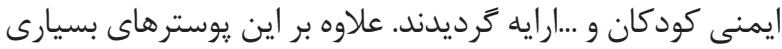

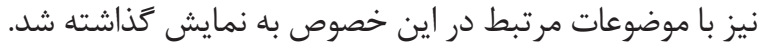

$$
\text { نتيجه گيرى }
$$

بعد از ץ روز بحث و تبادل نظر در اين گردهمايى، در يايان موارد

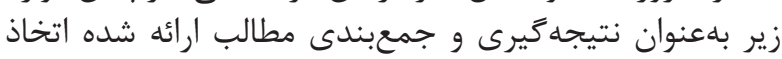

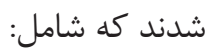
• (1) اعلام نمودن ايمنى جاده بهعنوان يك مشكل بهداشتى ملى • † (Y) تصويب استانداردهاى ايمنى فنى براى اتومبيل و صندلىهاى كودى

3. Peden MM. Adult Pedestrian Traffic Trauma in Cape Town with Special Reference to the Role of Alcohol [Unpublished Thesis]. Cape Town, University of Cape Town, Department of Surgery; 1997.

4. Andrew W. Howard. Automobile Restraints for Children: Clinicians. CMAJ. 2002; 167(7): 769-73. 